\title{
Article \\ Cellulose Microfibril and Micronized Rubber Modified Asphalt Binder
}

\author{
Ang Li ${ }^{1}$, Abdu A. Danladi ${ }^{2}$, Rahul Vallabh ${ }^{1}$, Mohammed K. Yakubu ${ }^{2}$, Umar Ishiaku ${ }^{2}$, Thomas Theyson ${ }^{1}(\mathbb{D}$ and \\ Abdel-Fattah M. Seyam ${ }^{1, *}$ \\ 1 Wilson College of Textiles, North Carolina State University, Raleigh, NC 27606, USA; ali10@ncsu.edu (A.L.); \\ rvallab@ncsu.edu (R.V.); tenstech@earthlink.net (T.T.) \\ 2 Department of Polymer and Textile Engineering, Ahmadu Bello University, Zaria 810107, Nigeria; \\ abduadanladi@gmail.com (A.A.D.); mkyakubu@abu.edu.ng (M.K.Y.); umaru@possiag.net (U.I.) \\ * Correspondence: aseyam@ncsu.edu; Tel.: +1-0919-515-6583
}

Citation: Li, A.; Danladi, A.A.;

Vallabh, R.; Yakubu, M.K.; Ishiaku, U.; Theyson, T.; Seyam, A.-F.M. Cellulose Microfibril and Micronized Rubber Modified Asphalt Binder. Fibers 2021, 9, 25. https://doi.org/10.3390/ fib9040025

Academic Editor:

Aliakbar Gholampour

Received: 7 January 2021

Accepted: 1 April 2021

Published: 7 April 2021

Publisher's Note: MDPI stays neutral with regard to jurisdictional claims in published maps and institutional affiliations.

Copyright: (c) 2021 by the authors. Licensee MDPI, Basel, Switzerland. This article is an open access article distributed under the terms and conditions of the Creative Commons Attribution (CC BY) license (https:// creativecommons.org/licenses/by/ $4.0 /)$.

\begin{abstract}
Cellulose microfibrils (CMFs) and micronized rubber powder (MRP) can be derived from low or negative-cost agricultural/industrial waste streams and offer environment-friendly and costeffective pathways to develop engineering products. This study investigated the efficacy of adding these micromodifiers on the performance characteristics of asphalt binders. In this work, samples were produced using a mixture of slow-setting anionic asphalt emulsion with various combinations of MRP (at 0, 2 and $10 \mathrm{wt} \%$ ) and four types of CMFs (hydrophobic and hydrophilic with crystalline ratios of $86 \%$ and $95 \%$ ) at 0,2 and $5 \mathrm{wt} \%$. The performance of modified asphalt samples was assessed by penetration depth (PD), softening point (SP), and penetration index (PI). Linear regression analysis showed that adding CMFs and/or MRP reduced PD and increased SP values. The type of CMFs significantly affected the performance, which becomes more distinct with the increased weight content of CMFs. While hydrophilic CMFs caused increases in SP and PI values, no clear trend was seen to determine the effect of CMF crystallinity. It was also discovered that the combined addition of CMF and MRP achieved similar PI values at lower total weight content compared to using MRP alone.
\end{abstract}

Keywords: cellulose microfibril; micronized rubber powder; asphalt binder; penetration depth; softening point; penetration index

\section{Introduction}

Increased traffic load combined with substantial temperature variations have been responsible for the asphalt pavement deterioration [1]. To mitigate or prevent pavement deteriorations, the development of modified asphalt binders by adding fibers, crumb rubbers, polymers, etc., has been the research focus over the past few decades [2-7]. Polymers can increase the viscosity of asphalt binders at high temperatures and increase their ductility at low temperatures. Studies have shown that adding polymer modifiers (e.g., polyphosphoric acid [2] and styrene-butadiene-styrene copolymer [3]) improves the viscoelastic properties of the asphalt binder by enlarging the temperature range over which asphalt mixtures can resist rutting and thermal cracking [1]. Crumb rubbers have been claimed to improve the viscosity, rheological properties, rutting resistance and thermal cracking of asphalt binders [8]. The performance of rubber modified asphalt binder depends mainly on the rubber type and binder and mixing condition. Fibers have also been found to stiffen asphalt by forming a fiber network [4]. The introduction of fibers into asphalt reinforces the binder system, thus increasing viscosity. The resulting modified asphalt binder has greater stability and possibly higher resistance to fatigue cracking than unmodified asphalt binders [4]. More recently, nanotechnology has emerged as a potential solution due to the small size and high surface area of nanoscale modifiers. Modifying asphalt with nano clay has been shown to reduce penetration depth and increase softening point, thus making 
modified binder to be more resistant to thermal cracking and rutting [9]. In general, the selection of an ideal modifier requires both engineering and economic considerations [10]. While the effects of various additives have been extensively investigated, only a few have been found to be satisfactory from both the performance and the cost points of view. For example, in the case of polymer modifiers, the phase separation issue of polymer-based additives [1], as well as their high cost [11], have made the use of polymers as modifiers restrictive. In recent years, sustainable asphalt modification technologies involving recycled waste materials have drawn growing attention and demands [12]. A range of recycled plastics was used to modify asphalt binders [13-15]. Kumar and Garg [16] investigated the rheology of waste plastic-fiber bitumen. It was found that the key properties of asphalt, such as penetration depth, softening point and ductility, improved with the addition of the waste fibers. In another study by S. Köfteci et al. [11], the optimum ratio of the fibers made of PVC waste was found to be as low as $3 \%$ to enhance asphalt performance. The utilization of discarded tires of vehicles was another step taken in this direction. The disposal of waste tires is a serious global environmental concern. In the past decades, many attempts have been made to modify asphalt binders using crumb rubbers made from discarded tires $[2,4,5]$, and adequate positive results proved its viability to improve asphalt performance. Crumb rubbers with relatively large and inconsistent particle sizes were commonly used to modify asphalt in previous research [17-19]. Yet, micronized rubber powder (MRP) made from discarded tires with new processing technology can be thoroughly cleaned and consistently sized to less than $100 \mu \mathrm{m}$. It has the advantage of easy dispersion into many systems and applications, which may be more effective to be used modifying asphalt. Cellulose microfibrils (CMFs) extracted from agricultural wastes also have the potential to be used to modify asphalt properties. CMFs can be obtained from soybean hulls, which are agricultural byproduct with negative values when the soybeans have been harvested and separated from the hulls. CMFs are bio-based, green materials with versatile intrinsic properties, e.g., high specific surface area, high crystallinity, and rich hydroxyl groups [20-22]. Innovative researches were conducted to explore their potential to be used as functional microfillers in textile finishing [23], medical textiles [24,25] and bio-nonwovens [26]. However, the application of CMFs to modify asphalt binder has not been investigated. V.S. Punith et al. [4] have compared the performance of asphalt binders modified by macroscale cellulose fibers and micronized rubber and claimed the advantage of using rubbers over fibers. With the emergence of CMFs, its effect of modifying asphalt is worth studying. Since the influence of adding CMFs alone or the combination of CMFs and MRP on asphalt binder performance has rarely been researched. The objective of this work was to address the lack of research in this area by examining asphalt performance characteristics, such as softening point (SP), penetration depth (PD), and penetration index (PI). The novelty of this research lies in the investigation of possible combined effect of using CMF and MRP compared with the effect of adding either CMF or MRP alone. Meanwhile, since most of the previous research on modified asphalt were conducted using synthetic and macroscale fibers, the utilization of microfibrils derived from agricultural waste to improve the asphalt properties is a potential alternative as well as a novel approach to realize more sustainable development.

\section{Materials and Methods}

\subsection{Materials}

This work used four grades of CMFs and one type of MRP to modify a slow-setting anionic asphalt emulsion of 40/50 penetration grade (sourced from Dalton Enterprise Inc., Cheshire, CT, USA) to study the impact of micromodifiers on the performance of asphalt. The flashpoint of this grade of asphalt emulsion is above $177^{\circ} \mathrm{C}$, and the specific gravity at $16^{\circ} \mathrm{C}$ is between $0.98-1.02 \mathrm{~g} / \mathrm{cc}$. The four grades of CMF (supplied by TensTech, Inc., Matthews, NC, USA) included hydrophilic (HPL) and hydrophobic (HPB) grades with crystalline ratios of $86 \%(\mathrm{LC})$ and $95 \%$ (HC). The MRP (MicroDyne ${ }^{\mathrm{TM}} 75-\mathrm{TR}$ acquired from Lehigh Technologies, Inc., Atlanta, GA, USA) is a 200-mesh grade with an average 
particle size of $\sim 75 \mu \mathrm{m}$. CMFs and MRP, shown in Figure $1 \mathrm{a}, \mathrm{b}$, is in powder form and easily dispersed in various systems. Additionally, both CMF (derived from soybean hull) and MRP (made from discarded tires) are inexpensive and sustainable materials.
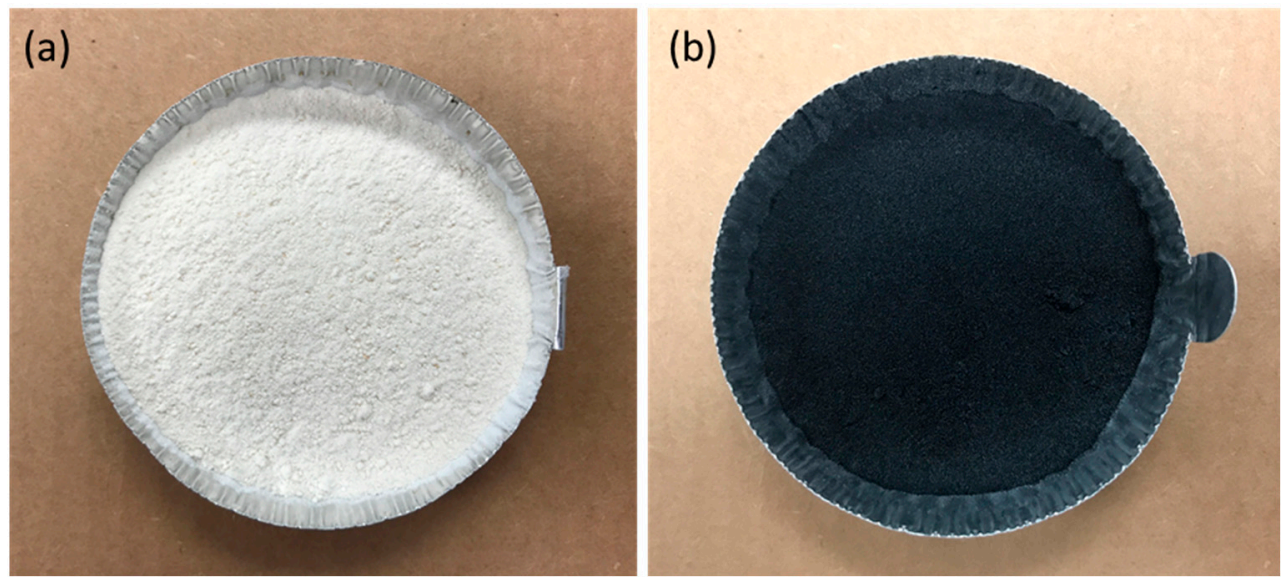

Figure 1. Images of (a) CMF and (b) MRP.

A total number of 27 control and modified asphalt samples were made according to the design of experiments shown in Table 1.

Table 1. Material variables for asphalt samples.

\begin{tabular}{cc}
\hline Material Variables & Values \\
\hline MRP wt $\%, R$ & $0,2,10$ \\
CMF wt $\%, F$ & $0,2,5$ \\
CMF type & HPL_LC, HPL_HC, HPB_LC, HPB_HC \\
\hline Number of samples & $3 \times(1+4+4)=27$ \\
\hline
\end{tabular}

\subsection{Asphalt Modification}

The most challenging part of preparing asphalt samples from asphalt emulsion is to effectively remove all water from the emulsion. In a previous work [27], asphalt emulsions were cast on pans and dried for three days, followed by forced air heating in an oven. However, in addition to being time-consuming, this method also does not guarantee the complete elimination of water in thick samples and maintaining uniform dispersion of modifiers during the drying period. Consequently, in this work, a new method was developed to efficiently produce control and modified samples with consistent quality. The method involved heating asphalt emulsion (mixed with additives in case of modified asphalt) in eliminating all water content and in melting the asphalt, followed by casting the melt in sample molds. To achieve and maintain uniform dispersion of additives in the emulsion, vigorous agitation (with a Thermo Scientific ${ }^{\mathrm{TM}}$ (Waltham, MA, USA) Cimarec ${ }^{\mathrm{TM}}$ digital stirring hotplate) was applied during the addition of modifiers to the emulsion and continued through the rest of the heating process. The heating process started with water evaporation in asphalt emulsion, followed by the eventual melting of the asphalt. With the increase in temperature, the mixtures with high concentration MRP ( $>5 \mathrm{wt} \%$ ) tended to become highly viscose, posing a challenge to thoroughly blending asphalt and modifiers. As a result, it took longer durations to prepare these samples. The temperature and weight of the sample were recorded every $15 \mathrm{~min}$ to determine the complete evaporation of water. The sample preparation was considered complete when weight remains equal for three consecutive readings indicating complete evaporation of water. The temperature recorded at this point was generally $\sim 300{ }^{\circ} \mathrm{C}$, which ensured that the asphalt was in melt form and ready to be cast in sample molds for penetration depth and softening point tests (Figure 2). 


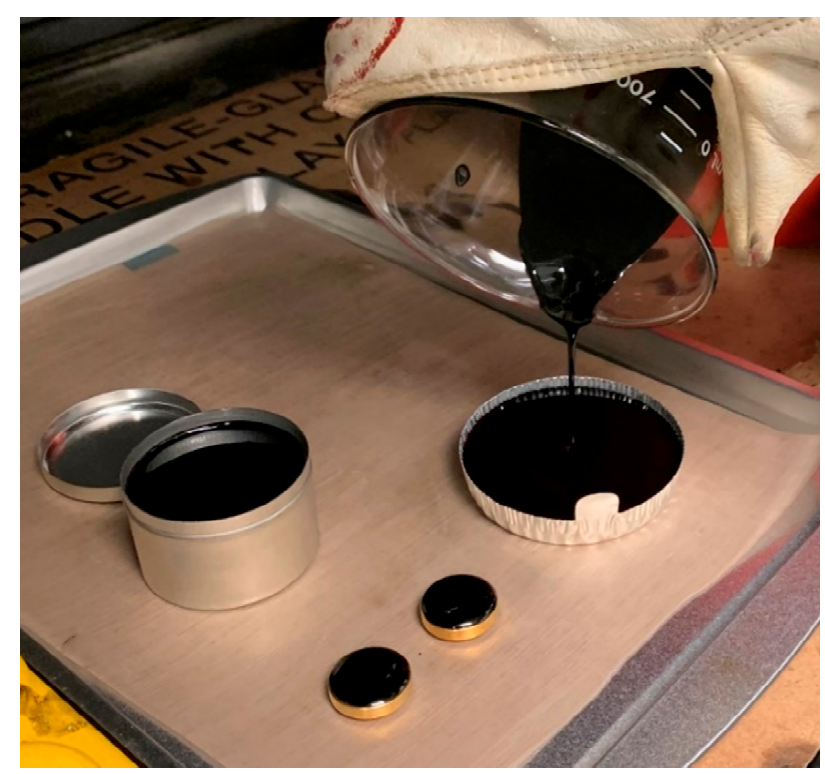

Figure 2. Asphalt in melt form being cast in sample molds for penetration depth and softening point tests.

\subsection{Characterization of Modified Asphalt}

Physical properties of the modified asphalt (and control) samples were characterized using standard test methods. Penetration depth tests were conducted at $25^{\circ} \mathrm{C}$ following ASTM D5-05 standard [28] using a Humboldt Mfg. Co. (Norridge, IL, USA) H-1250 Penetrometer. Per the ASTM standard, three readings were obtained from different locations of each specimen. Softening point tests were completed following the ASTM D36-06 standard [29] with a Humboldt Mfg. Co. H-1569 Ring and Ball Apparatus. For the softening point test, two readings were obtained for each specimen since the double-ring frame was used. Additionally, the penetration index (PI) was calculated according to Equation (1) [27] to determine the temperature susceptibility of the modified asphalt samples:

$$
\mathrm{PI}=\left[1952-500 *\left(\mathrm{Pen}_{25}-20 * \mathrm{SP}\right)\right] /\left[50 * \log \left(\mathrm{Pen}_{25}-\mathrm{SP}\right)-120\right]
$$

where $\mathrm{Pen}_{25}$ is penetration depth at $25^{\circ} \mathrm{C}$ and SP is softening point.

\section{Results and Discussion}

\subsection{Penetration Depth and Softening Point}

Regression models for penetration depth (Equation (2)) and softening point (Equation (3)) were developed using $81(27 \times 3)$ penetration depth and $54(27 \times 2)$ softening point readings obtained in Section 2.3, respectively. The regression models for penetration depth (PD) and softening point (SP) with R-squared values of 0.80 and 0.96 , respectively, showed that all variables, including CMF type, CMF weight content $(F)$ and MRP content $(R)$, significantly affected penetration depth and softening point:

$$
\begin{gathered}
\mathrm{PD}=-0.965 * \mathrm{HPL} \_\mathrm{LC} * \mathrm{~F}-0.919 * \mathrm{HPL} \_\mathrm{HC} * \mathrm{~F}-0.479 * \mathrm{HPB} \_\mathrm{LC} * \mathrm{~F}-1.218 * \mathrm{HPB} \_\mathrm{HC} * \mathrm{~F}-0.862 * \mathrm{R}+46.766 \\
\mathrm{SP}=1.053 * \mathrm{HPL} \_\mathrm{LC} * \mathrm{~F}+0.915 * \mathrm{HPL} \_\mathrm{HC} * \mathrm{~F}+0.498 * \mathrm{HPB} \_\mathrm{LC} * \mathrm{~F}+0.680 * \mathrm{HPB} \_\mathrm{HC} * \mathrm{~F}+1.135 * \mathrm{R}+39.217
\end{gathered}
$$

The effect of variables, including MRP content and CMF type at different CMF weight contents $(0 \%, 2 \%$ and $5 \%)$ on PD, is shown in Figures 3 and 4, respectively. The effect of these variables on the SP is shown in Figures 5 and 6. 


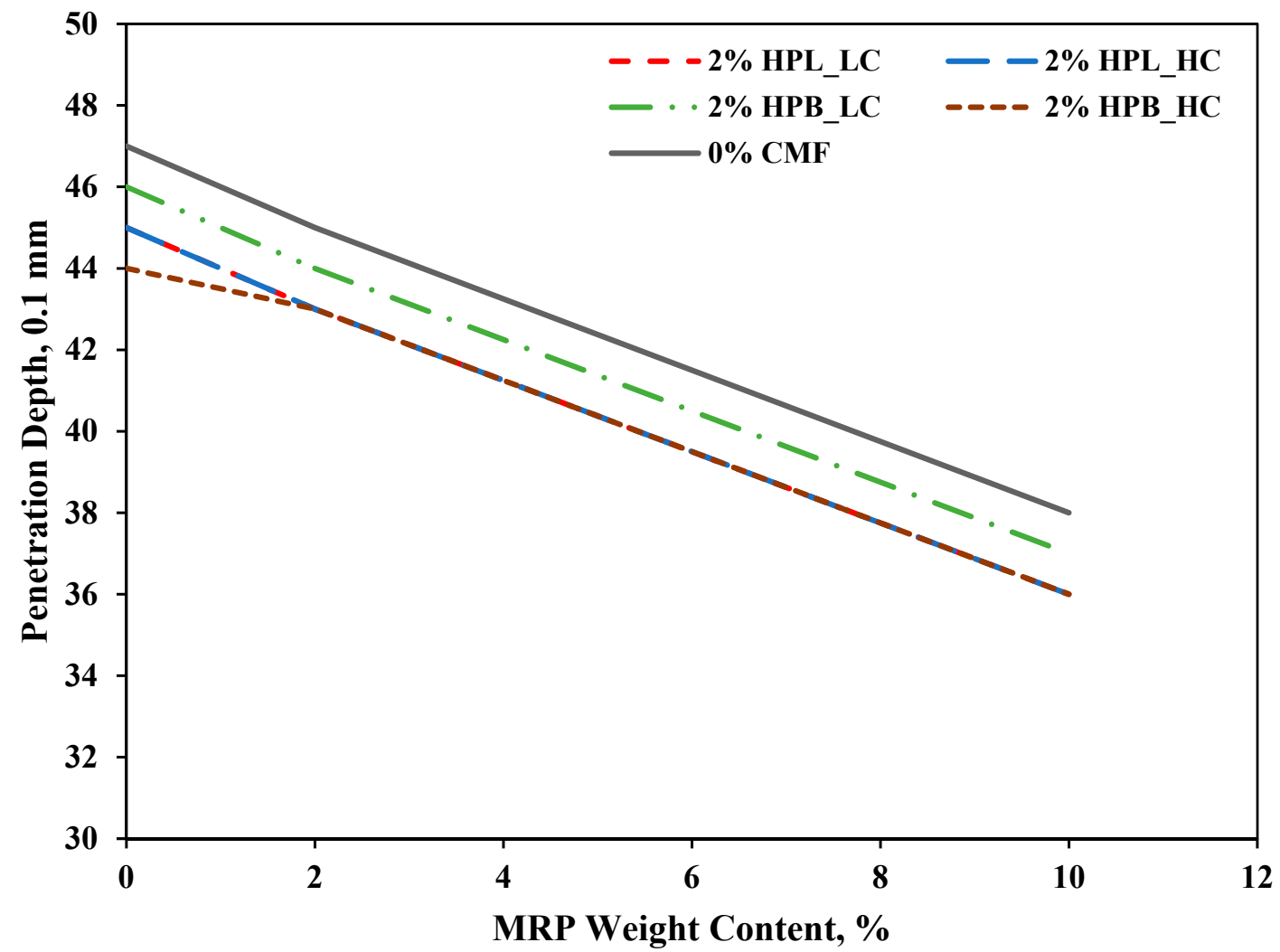

Figure 3. Effect of micronized rubber powder (MRP) content and cellulose microfibrils (CMF) type on penetration depth at $0 \%$ and $2 \%$ CMF content.

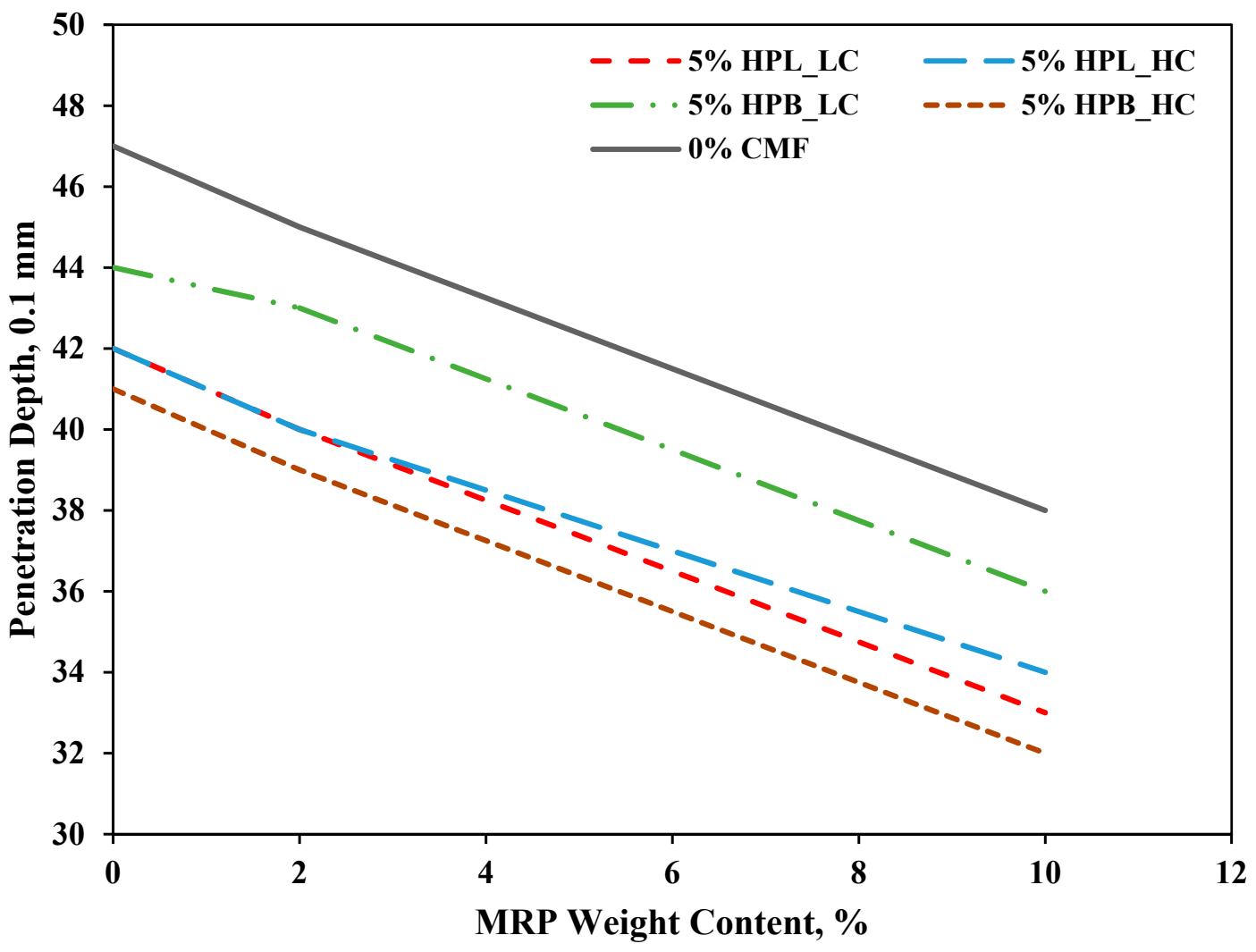

Figure 4. Effect of MRP content and CMF type on penetration depth at $\%$ and $5 \% \mathrm{CMF}$ content. 


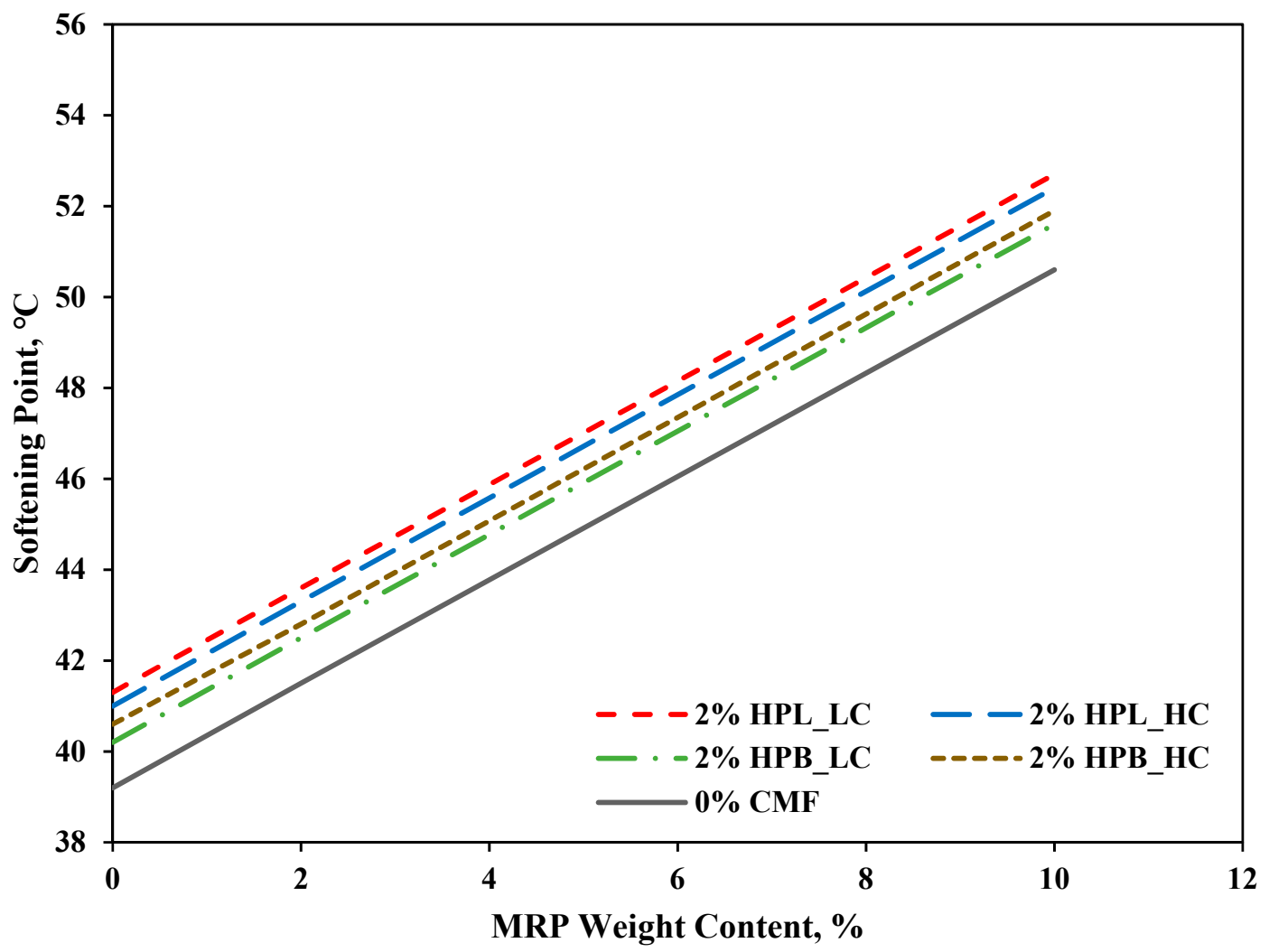

Figure 5. Effect of MRP content and CMF type on softening point at $0 \%$ and $2 \%$ CMF content.

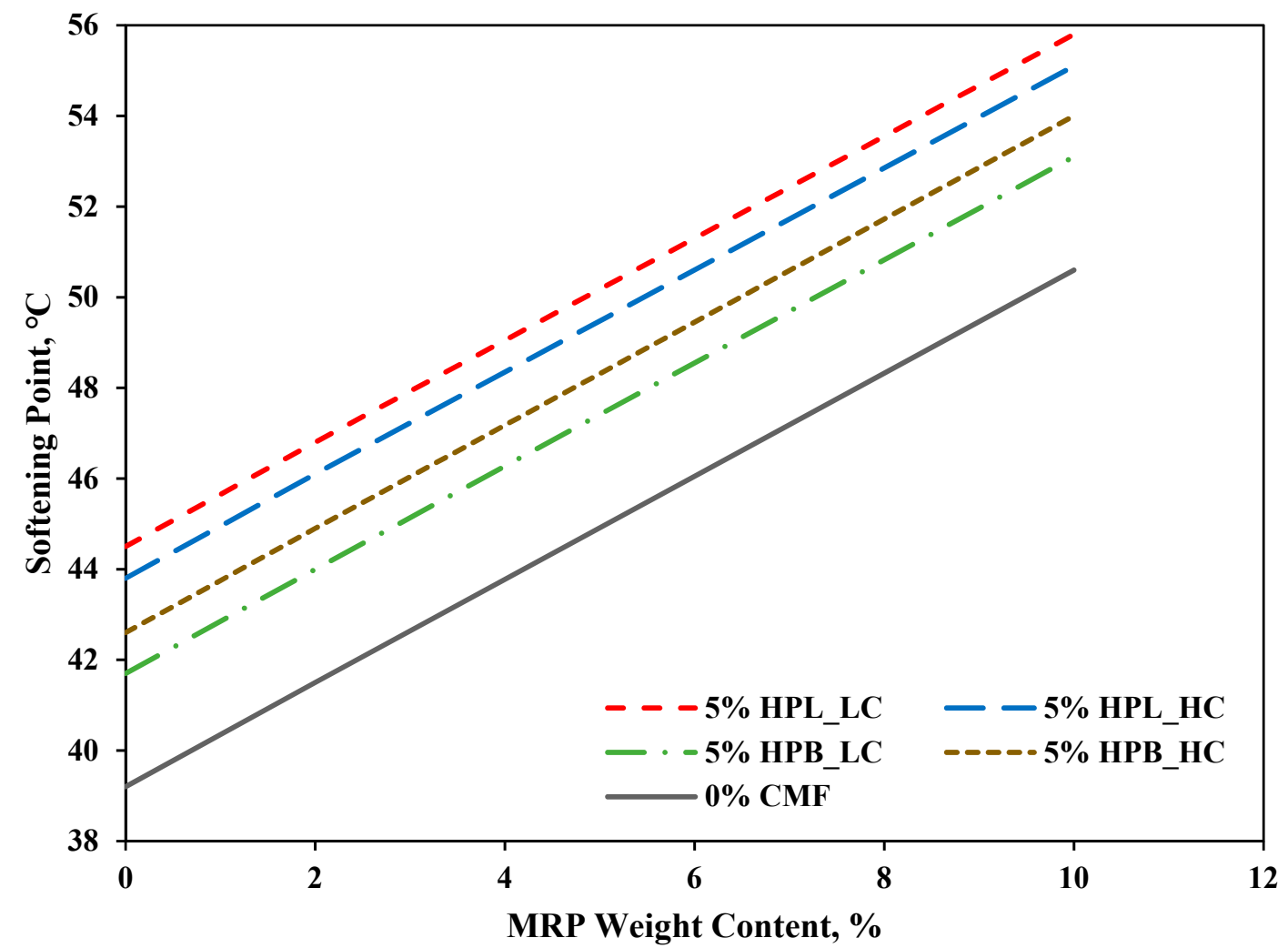

Figure 6. Effect of MRP content and CMF type on softening point at $0 \%$ and $5 \% \mathrm{CMF}$ content. 
The penetration depth (PD) at $25{ }^{\circ} \mathrm{C}$ and softening point (SP) of unmodified asphalt were found to be 47.7 (units $0.1 \mathrm{~mm}$ ) and $39.3^{\circ} \mathrm{C}$, respectively. The addition of MRP and/or CMF to asphalt significantly modified its penetration depth and softening point characteristics. With the increase in MPR and/or CMF content, penetration depth decreased, whereas the softening point increased proportionately. These phenomena can be explained by the interaction mechanism of asphalt with MPR and CMF. When the MRPs are immersed in hot asphalt, the lighter molecular weight component of asphalt is absorbed into the rubber particle, making them swell up to 5 times their original volume [30]. The absorption of the lighter components not only results in reduced interparticle space (due to swelling) but also stiffens in the binder present in the interparticle space [31]. The addition of CMF resulted in the further stiffening of the higher molecular component (asphaltene) present in the interparticle space. Additionally, PD and SP were also significantly affected by the type of CMF, with the effect becoming more distinct in modified asphalt with higher CMF content. However, despite the regression analysis showing a significant effect of CMF type on penetration depth, a clear trend explaining the effect of hydrophilicity and crystallinity could not be established. In contrast, regression analysis of the softening point results clearly showed that the addition of hydrophilic CMF, compared to hydrophobic CMF, resulted in a higher softening point. This can be attributed to the higher affinity between the hydrophilic CMF and the polar asphaltene component. However, the effect of CMF crystallinity did not show a clear trend. The lack of clarity on the specific effect of hydrophilicity and crystallinity is attributed to the variation in results caused by specimen uniformity and measurement errors. However, the distinctive nature of the result pertaining to CMF type provides strong evidence indicating the significance of CMF type on the PD and SP characteristics of modified asphalt.

Comparison of asphalt samples with only MRP or CMF showed that the addition of some types of CMF resulted in lower penetration depth compared to that resulting from the addition of MRP. This may be attributed to the three-dimensional spatial networking effect of CMFs [32]. As shown in Figure 7, rod-like CMFs with higher length-to-width ratios have better spatial network formation capability than spherical or irregular-shaped MRPs. This effect can be more significant as the additive contents in the asphalt mixture were below $10 \%$ in this work. The stereomicroscopic images in Figure 7 show that CMFs are smaller and have larger specific surface area compared with MRPs. In contrast, modified samples with only MRP resulted in a higher softening point than that of samples modified with only CMF. Although MRPs have smaller specific surface areas, they are still effective in stabilizing asphalt and provide good interfacial adhesion, which may be due to the solubility law [32] since the chemical affinity between MRPs and asphalt is much higher. Stronger interactions between additives and asphalt would result in better high-temperature stability and, therefore, the higher softening point of the mixtures.

\subsection{Penetration Index}

The effect of CMF type, CMF content and MRP content on the penetration index (PI) was investigated using the regression model shown in Equation (4). The regression model had an R-squared value of 0.95 with variables CMF type, CMF content and MRP content significantly affecting penetration index (at 95\% confidence level).

$$
\mathrm{PI}=0.243 * \mathrm{HPL} \_\mathrm{LC} * \mathrm{~F}+0.212 * \mathrm{HPL} \_\mathrm{HC} * \mathrm{~F}+0.137 * \mathrm{HPB} \_\mathrm{LC} * \mathrm{~F}+0.174 * \mathrm{HPB} \_\mathrm{HC} * \mathrm{~F}+0.218 * \mathrm{R}-3.665
$$

PI is an important metric that is used to assess the temperature susceptibility of asphalt binders with lower PI values indicating higher temperature susceptibility. As an example, the PI values in the range from -2 to +2 are considered suitable for use in pavement application. Asphalt binders with PI values below -2 are highly susceptible to temperature and are prone to becoming brittle at low temperatures, which results in a higher tendency to thermal cracking and rutting [33]. 


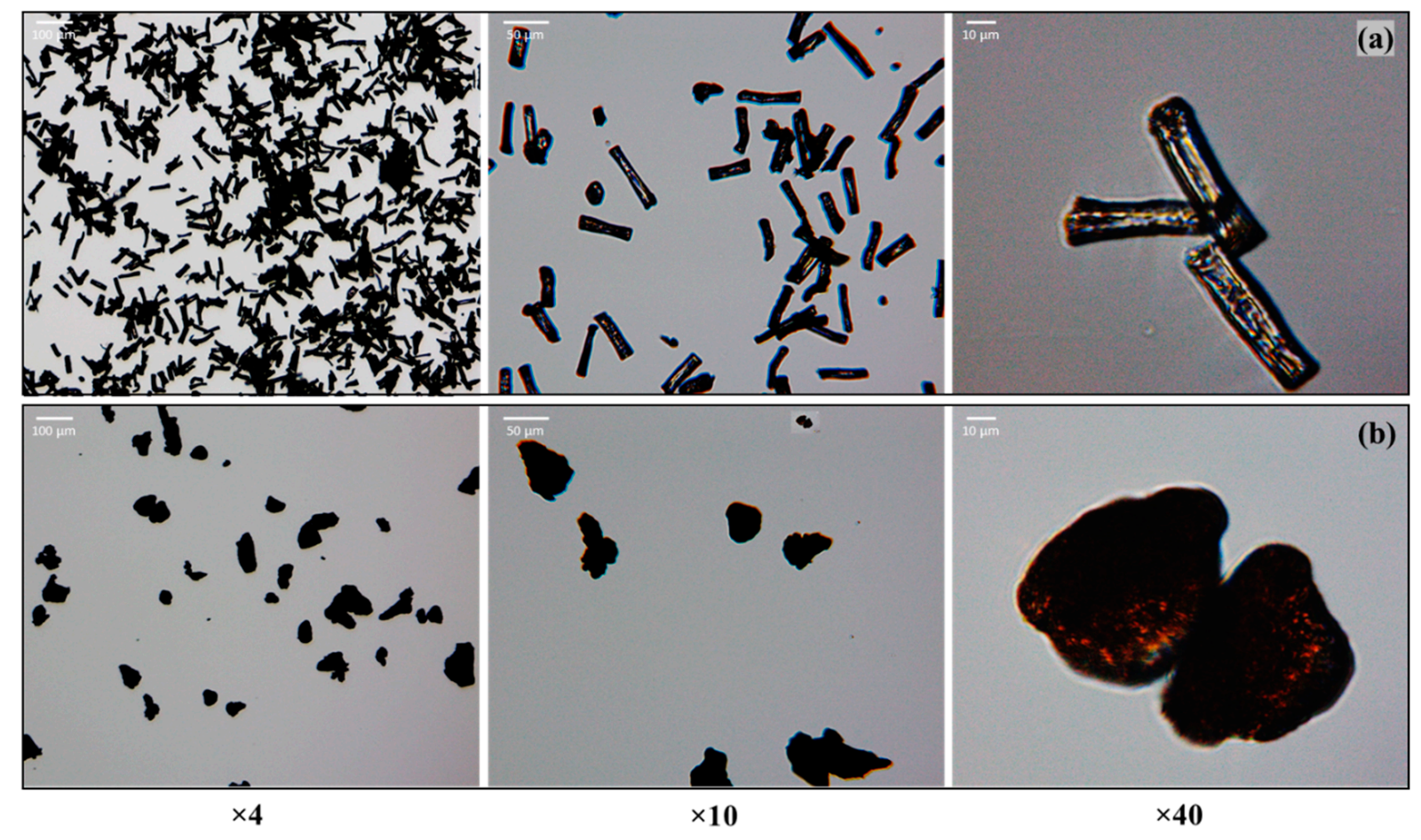

Figure 7. Stereomicroscopic images of (a) CMFs and (b) MRPs at different magnifications.

The effect of variables, including MRP content and CMF type at different CMF weight contents $(0 \%, 2 \%$ and $5 \%)$ on PI is shown in Figures 8 and 9 , respectively. Unmodified asphalt binder had a PI value less than -3.7 and is, therefore, prone to becoming brittle at low temperatures. Modifying asphalt with the addition of MRP and/or CMF significantly improved its temperature susceptibility, with PI linearly increasing as the additive content increased. The PI value was also significantly affected by the type of CMF. However, the PI value differences were not significant at $2 \%$ but more distinct at 5\% CMF weight content.

Additionally, regression analysis showed that hydrophilic CMFs resulted in higher PI values. However, a clear trend describing the effect of the degree of crystallinity could not be established. It was also found that combined addition of CMF and MRP achieved similar PI values at lower total additive weight content compare to the addition of MRP alone. For example, asphalt binder modified with MRP alone required $8 \%$ or higher additive weight content to achieve PI in the -2 to +2 PI range. In comparison, asphalt modified by combined addition of CMF and MRF required 6\% (2\% CMF and 4\% MRP) or more total additive weight content to achieve the same range of PI value. Moreover, the addition of high content of rubbers in the asphalt binder resulted in a substantial increase in the viscosity of their modified asphalt due to the swelling of rubber, which would negatively affect the processability performance for the asphalt. In contrast, the addition of CMF did not have any significant effect on the viscosity of the modified asphalt. 


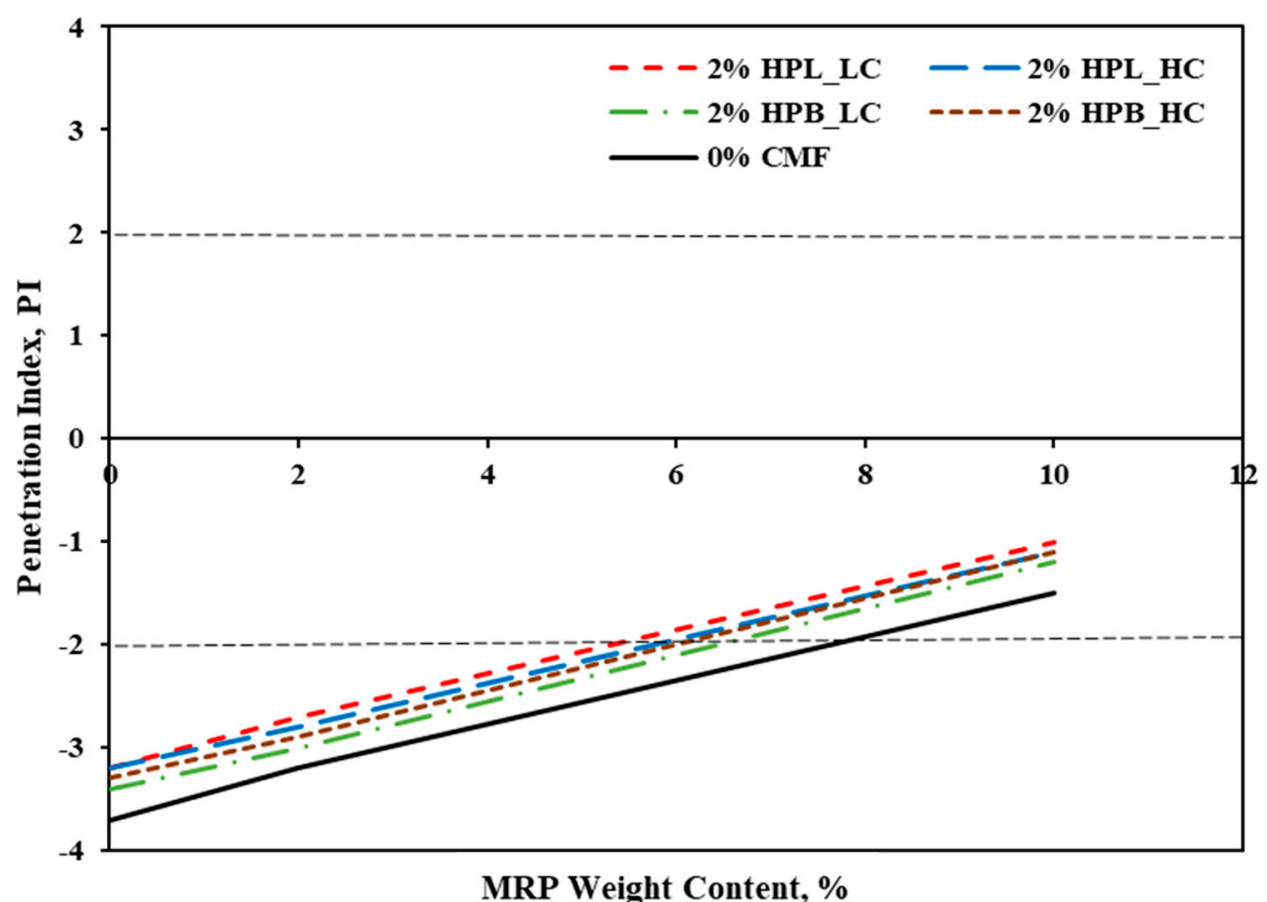

Figure 8. Effect of MRP content and CMF type on penetration index at $2 \% \mathrm{CMF}$ content.

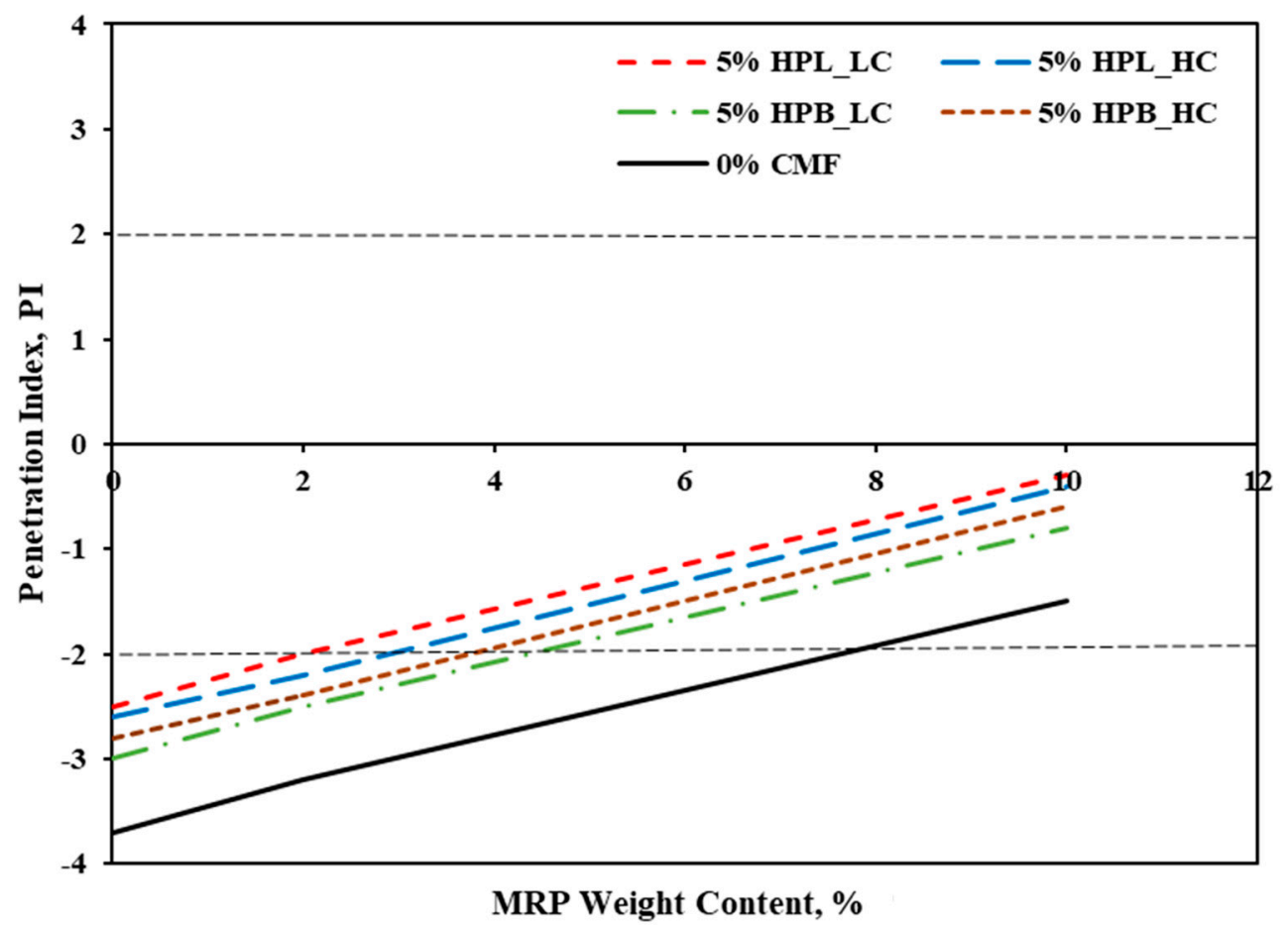

Figure 9. Effect of MRP content and CMF type on penetration index at 5\% CMF content.

\section{Conclusions}

The efficacy of modifying asphalt performance characteristics by additives, including four types of cellulose microfibrils (CMFs) and micronized rubber powder (MRP), was investigated. Linear regression analysis showed that the addition of CMFs and/or MRP reduced the penetration depth and increased softening point values; however, the higher weight content of the MRP resulted in a higher viscosity of the mixture, which could present processing challenges. The type of CMF was found to significantly affect the 
performance characteristics of the modified asphalt, which become more distinct with the increased content of CMFs. While hydrophilic CMFs in general increased the softening point and penetration index, no clear trend was seen to determine the effect of CMF crystallinity. The penetration index of unmodified asphalt was found to be -3.7 . It was possible to achieve a penetration index in the range of -2 to 2 (suitable for asphalt applications) by the addition of MRP and/or CMFs. It was also found that combined addition of CMFs and MRP achieved similar PI values at lower total additive weight content compare to the addition of MRP alone. Our work sheds light on opportunities of designing enhanced asphalt performance using inexpensive additives while addressing environmental issues. To further validate the efficacy of CMF and MRP modifications on asphalt binder performance, more future research work is recommended. SEM imaging analysis and chemistry analysis via FTIR need to be done to evaluate the fiber-asphalt and rubber-asphalt interfaces and better understand the bonding mechanism. Contact angle measurements and systematic thermal analysis are required to examine the key performances of asphalt to be properly used in civil applications and verify our PI value findings in this work.

Author Contributions: Conceptualization, A.A.D., A.L. and R.V.; methodology, A.A.D. and A.L.; validation, R.V. and A.-F.M.S.; formal analysis, R.V.; investigation, A.L. and A.A.D.; resources, T.T.; data curation, A.A.D. and A.L.; writing—original draft preparation, A.L. and R.V.; writing—review and editing, A.L., R.V., A.-F.M.S. and M.K.Y.; visualization, A.L. and R.V.; supervision, A.-F.M.S. and M.K.Y.; project administration, A.-F.M.S. and M.K.Y.; funding acquisition, A.-F.M.S., M.K.Y. and U.I. All authors have read and agreed to the published version of the manuscript.

Funding: This research was funded by Tertiary Education Trust Fund, Nigeria and North Carolina State University, NC, USA.

Institutional Review Board Statement: Not applicable.

Informed Consent Statement: Not applicable.

Data Availability Statement: The data presented in this study are available on request from the corresponding author. The data are not publicly available due to privacy.

Conflicts of Interest: The authors declare no conflict of interest. The funders had no role in the design of the study, in the collection, analyses, or interpretation of data, in the writing of the manuscript, or in the decision to publish the results.

\section{References}

1. Behnood, A.; Modiri Gharehveran, M. Morphology, rheology, and physical properties of polymer-modified asphalt binders. Eur. Polym. J. 2019, 112, 766-791. [CrossRef]

2. Behnood, A.; Olek, J. Rheological properties of asphalt binders modified with styrene-butadiene-styrene (SBS), ground tire rubber (GTR), or polyphosphoric acid (PPA). Constr. Build. Mater. 2017, 151, 464-478. [CrossRef]

3. Vlachovicova, Z.; Wekumbura, C.; Stastna, J.; Zanzotto, L. Creep characteristics of asphalt modified by radial styrene-butadienestyrene copolymer. Constr. Build. Mater. 2007, 21, 567-577. [CrossRef]

4. Punith, V.S.; Suresha, S.N.; Raju, S.; Bose, S.; Veeraragavan, A. Estimating Welfare Change Associated with Improvements in Urban Bicycling Facilities. J. Transp. Eng. 2015, 138, 548-556. [CrossRef]

5. González, V.; Martínez-Boza, F.J; Navarro, FJ.; Gallegos, C.; Pérez-Lepe, A.; Páez, A. Thermomechanical properties of bitumen modified with crumb tire rubber and polymeric additives. Fuel Process. Technol. 2010, 91, 1033-1039. [CrossRef]

6. Özen, H.; Aksoy, A.; Tayfur, S.; Çelik, F. Laboratory performance comparison of the elastomer-modified asphalt mixtures. Build. Environ. 2008, 43, 1270-1277. [CrossRef]

7. Al-Dubabe, I.A.; Al-Abdul Wahhab, H.I.; Asi, I.M.; Ali, M.F. Polymer modification of Arab asphalt. J. Mater. Civ. Eng. 1998, 10, 161-167. [CrossRef]

8. Yao, H.; You, Z.; Li, L.; Goh, S.W.; Lee, C.H.; Yap, Y.K.; Shi, X. Rheological properties and chemical analysis of nanoclay and carbon microfiber modified asphalt with Fourier transform infrared spectroscopy. Constr. Build. Mater. 2013, 38, 327-337. [CrossRef]

9. Abdullah, M.E.; Zamhari, K.A.; Hainin, M.R.; Oluwasola, E.A.; Hassan, N.A.; Yusoff, N.I.M. Engineering properties of asphalt binders containing nanoclay and chemical warm-mix asphalt additives. Constr. Build. Mater. 2016, 112, 232-240. [CrossRef]

10. Coplantz, J.S.; Yapp, M.T.; Finn, F.N. Review of Relationships between Modified Asphalt Properties and Pavement Performance. 1993. Available online: http:// onlinepubs.trb.org/onlinepubs/shrp/SHRP-A-631.pdf (accessed on 25 June 2020). 
11. Köfteci, S.; Ahmedzade, P.; Kultayev, B. Performance evaluation of bitumen modified by various types of waste plastics. Constr. Build. Mater. 2014, 73, 592-602. [CrossRef]

12. Cuadri, A.A.; Roman, C.; García-Morales, M.; Guisado, F.; Moreno, E.; Partal, P. Formulation and processing of recycled-lowdensity-polyethylene-modified bitumen emulsions for reduced-temperature asphalt technologies. Chem. Eng. Sci. 2016, 156, 197-205. [CrossRef]

13. Fang, C.; Hu, J.; Zhou, S.; Wang, H.; Zhang, M.; Zhang, Y. Comparative study of asphalts modified by packaging waste EPS and waste PE. Polym. Plast. Technol. Eng. 2011, 50, 220-224. [CrossRef]

14. García-Morales, M.; Partal, P.; Navarro, F.J.; Gallegos, C. Effect of waste polymer addition on the rheology of modified bitumen. Fuel 2006, 85, 936-943. [CrossRef]

15. Naskar, M.; Chaki, T.K.; Reddy, K.S. Effect of waste plastic as modifier on thermal stability and degradation kinetics of bitumen/waste plastics blend. Thermochim. Acta 2010, 509, 128-134. [CrossRef]

16. Kumar, P.; Garg, R. Rheology of waste plastic fibre-modified bitumen. Int. J. Pavement Eng. 2011, 12, 449-459. [CrossRef]

17. Sienkiewicz, M.; Borzędowska-Labuda, K.; Zalewski, S.; Janik, H. The effect of tyre rubber grinding method on the rubber-asphalt binder properties. Constr. Build. Mater. 2017, 154, 144-154. [CrossRef]

18. Liu, S.; Cao, W.; Fang, J.; Shang, S. Variance analysis and performance evaluation of different crumb rubber modified (CRM) asphalt. Constr. Build. Mater. 2009, 23, 2701-2708. [CrossRef]

19. Jeong, K.D.; Lee, S.J.; Amirkhanian, S.N.; Kim, K.W. Interaction effects of crumb rubber modified asphalt binders. Constr. Build. Mater. 2010, 24, 824-831. [CrossRef]

20. Merci, A.; Urbano, A.; Grossmann, M.V.E.; Tischer, C.A.; Mali, S. Properties of microcrystalline cellulose extracted from soybean hulls by reactive extrusion. Food Res. Int. 2015, 73, 38-43. [CrossRef]

21. Kalia, S.; Boufi, S.; Celli, A.; Kango, S. Nanofibrillated cellulose: Surface modification and potential applications. Colloid Polym. Sci. 2014, 292, 5-31. [CrossRef]

22. González, A.; Gastelú, G.; Barrera, G.N.; Ribotta, P.D.; Álvarez Igarzabal, C.I. Preparation and characterization of soy protein films reinforced with cellulose nanofibers obtained from soybean by-products. Food Hydrocoll. 2019, 89, 758-764. [CrossRef]

23. Hebeish, A.; Farag, S.; Sharaf, S.; Shaheen, T.I. High performance fabrics via innovative reinforcement route using cellulose nanoparticles. J. Text. Inst. 2018, 109, 186-194. [CrossRef]

24. Farooq, A.; Jiang, S.; Farooq, A.; Naeem, M.A.; Ahmad, A.; Liu, L. Structure and properties of high quality natural cellulose nano fibrils from a novel material Ficus natalensis barkcloth. J. Ind. Text. 2019. [CrossRef]

25. Yazdanbakhsh, M.F.; Rashidi, A. The effect of ultrasonic waves on alpha-cellulose extraction from wheat bran to prepare alpha-cellulose nanofibers. J. Text. Inst. 2020, 111, 1518-1529. [CrossRef]

26. Ashjaran, A.; Yazdanshenas, M.E.; Rashidi, A.; Khajavi, R.; Rezaee, A. Overview of bio nanofabric from bacterial cellulose. J. Text. Inst. 2013, 104, 121-131. [CrossRef]

27. Khadivar, A.; Kavussi, A. Rheological characteristics of SBR and NR polymer modified bitumen emulsions at average pavement temperatures. Constr. Build. Mater. 2013, 47, 1099-1105. [CrossRef]

28. ASTM D5-05 Standard Test Method for Penetration of Bituminous Materials. ASTM Int. 2008, 1-4. [CrossRef]

29. ASTM D36-06 Standard Test Method for Softening Point of Bitumen (Ring-and-Ball Apparatus). ASTM Int. 2008, 1-4. [CrossRef]

30. Gawel, I.; Stepkowski, R.; Czechowski, F. Molecular interactions between rubber and asphalt. Ind. Eng. Chem. Res. 2006, 45, 3044-3049. [CrossRef]

31. Blanchoin, L.; Blanchoin, L.; Pollard, T.D.; Pollard, T.D. Mechanism of Interaction of Cement with Crumb Rubber Modifier. Biochemistry 1999, 274, 15538-15546.

32. Chen, H.; Xu, Q. Experimental study of fibers in stabilizing and reinforcing asphalt binder. Fuel 2010, 89, 1616-1622. [CrossRef]

33. Enieb, M.; Diab, A. Characteristics of asphalt binder and mixture containing nanosilica. Int. J. Pavement Res. Technol. 2017, 10, 148-157. [CrossRef] 